\title{
Simplified methods for designing thermo-active retaining walls
}

\author{
Eleonora Sailer ${ }^{1,}$, David M. G. Taborda ${ }^{1}$, Lidija Zdravkovic $^{1}$ and David M. Potts ${ }^{1}$ \\ ${ }^{1}$ Department of Civil and Environmental Engineering, Skempton Building, Imperial College London, London, United Kingdom
}

\begin{abstract}
Thermo-active retaining structures are geotechnical structures employed to provide thermal energy to buildings for space heating and cooling through heat exchanger pipes embedded within the concrete structure. Consequently, the design of these structures needs to consider both the long-term energy efficiency as well as the thermo-mechanical response in terms of stability and serviceability. Transient finite element analyses can be carried out to evaluate the behaviour of thermo-active walls, where the heat exchanger pipes are explicitly modelled, thus requiring three-dimensional (3D) analyses. However, performing long-term 3D finite element analyses is computationally expensive. For this reason, in this study, new approaches are presented that allow the thermal or thermo-mechanical design of thermo-active walls to be carried out by performing two-dimensional (2D) plane strain analyses. Two methods, which are based on different design criteria, are proposed and their performance in replicating the three-dimensional behaviour is assessed. Furthermore, the factors affecting the 2D approximations for the two modelling approaches are evaluated, where particular emphasis is given to the influence of the simulated boundary condition along the exposed face of the retaining wall.
\end{abstract}

\section{Introduction}

Thermo-active retaining walls are employed to produce thermal energy for space heating and cooling. This is achieved by installing heat exchanger pipes within the structure, which, through the circulation of a hot or cold fluid, inject or extract energy to/from the ground, respectively. Hence, this type of structure has the dual purpose of providing both energy and stability to buildings. As such, these two aspects, i.e. energy efficiency and structural performance (both in terms of stability and serviceability), are of concern when designing thermo-active walls.

Limited field work has been carried out to characterise the thermal and thermo-mechanical behaviour of walls [1$3]$. For this reason, the response of thermo-active walls has been investigated through numerical analysis to evaluate their energy efficiency (e.g. [4]) or structural response (e.g. [5]). Due to the presence of heat exchanger pipes, which lead to non-uniform temperature distributions along the width of the wall panel, these problems are inherently three-dimensional (3D). However, due to the dimensions of the analysed problem and the need to employ a coupled thermo-hydromechanical (THM) formulation [6], performing threedimensional (3D) analyses is computationally expensive. Thus, thermo-active walls are often simulated in twodimensional (2D) plane strain analyses, although no modelling procedures which ensure that the response in $2 \mathrm{D}$ is comparable to that obtained in $3 \mathrm{D}$ have been proposed in the literature.

This paper seeks to address this issue by presenting two modelling approaches that enable the estimation of the energy efficiency (thermal design) and structural performance (thermo-mechanical design) of thermoactive walls using 2D plane strain finite element analyses. It should be noted that, although the proposed 2D approximations were established assuming that the heat exchanger pipes form U-loops, the general methodology described in this paper can be extended to include any pipe arrangement. The simulations reported herein are carried out employing the Imperial College Finite Element Program (ICFEP, [7]), which is capable of simulating fully coupled THM problems [8] and the heat transfer occurring within heat exchanger pipes through the use of one-dimensional elements $[9,10]$. The validity of the proposed 2D approximations is demonstrated by simulating a thermo-active wall problem using 3D analyses and comparing the results to those obtained by the corresponding 2D analyses. The adopted sign convention is such that positive values refer to tensile axial forces, bending moment as a result of tension along the excavated side of the wall and upward vertical movements.

\section{Problem description and numerical model in three-dimensional analysis}

Figure 1 depicts a schematic representation of the analysed problem and Figure 2 shows the finite element (FE) mesh. The thermo-active wall, of which a single panel is modelled, is embedded entirely in London Clay. It is $20.0 \mathrm{~m}$ long $(L), 1.0 \mathrm{~m}$ thick $(W)$ and $2.0 \mathrm{~m}$ wide $(B)$ and supports a $30.0 \mathrm{~m}$ wide and $16.0 \mathrm{~m}$ deep $\left(L_{\text {exp }}\right)$ excavation. The wall is supported by horizontal slabs (see

*Corresponding author: eleonora.sailer13@imperial.ac.uk 
Figure 2), where the floor slabs and the base slab were assumed to have thicknesses of $0.3 \mathrm{~m}$ and $1.0 \mathrm{~m}$, respectively. The mechanical boundary conditions include a restraint in the vertical direction along the bottom boundary and in the horizontal directions along the normal direction to each lateral boundary. The heat exchanger pipes (internal diameter of $27.33 \mathrm{~mm}$ ) are located at a distance of $0.1 \mathrm{~m}$ from the concrete edge on the retained side, with a pipe-to-pipe spacing of $1.0 \mathrm{~m}$, and reach a depth of $19.5 \mathrm{~m}$. The initial ground conditions consist of a hydrostatic pore water pressure profile, with the water table located at the ground surface, a coefficient of earth pressure at rest, $K_{0}$, of 1.0 , and a saturated bulk unit weight of soil, $\gamma$, equal to $20 \mathrm{kN} / \mathrm{m}^{3}$. Two different conditions were assumed for the wall-air interaction along the exposed face: no heat flux takes place across this boundary (NF) and a wall face maintained at constant temperature equal to the initial temperature $\left(T_{0}\right)$ of $15^{\circ} \mathrm{C}$ (CT), i.e. similar to those adopted in [11].

The concrete and heat exchanger pipes were modelled as linear-elastic materials, with the former having a Young's modulus, $E$, of $30 \mathrm{GPa}$ and a Poisson's ratio, $v$, of 0.3 , while the latter have a sufficiently low stiffness such that they do not affect the response of the wall. The soil was modelled as a non-linear elasto-plastic material, with a Mohr-Coulomb failure surface $\left(c^{\prime}=5.0 \mathrm{kPa}\right.$, $\left.\varphi^{\prime}=25.0^{\circ}, \psi^{\prime}=12.5^{\circ}\right)$ coupled with the IC.G3S non-linear elastic stiffness model [12]. The employed parameters for London Clay are adopted from [13]. The soil has a permeability of $1.0 \times 10^{-10} \mathrm{~m} / \mathrm{s}$ and the coefficient of expansion of water, $\alpha_{w}$, is equal to $6.9 \times 10^{-5} \mathrm{~m} / \mathrm{mK}$. All materials present the same coefficient of thermal expansion, $\alpha$, of $1.2 \times 10^{-6}$. The thermal material properties are outlined in Table 1.

The rapid excavation was simulated by removing $2.0 \mathrm{~m}$ thick soil layers until the excavation depth was reached. During this stage, temporary props at depths of $3.0 \mathrm{~m}, 7.0 \mathrm{~m}$ and $11.0 \mathrm{~m}$, simulated as a nodal spring with a stiffness of $100 \mathrm{MN} / \mathrm{m}$ applied to the middle of the wall panel, supported the excavation. These were removed after completion of the excavation, when the permanent slabs were constructed, modelled as springs normal to the wall surface along the whole width of the panel, simulating concrete slabs ( $E=28 \mathrm{GPa}$ ). Subsequently, six months of heat injection were modelled by imposing an inlet temperature, $T_{i n, 3 D}$, of $30^{\circ} \mathrm{C}$ (corresponding to a difference between the inlet and initial temperature, $\Delta T_{\text {in }, 3 \mathrm{D}}$, of $15^{\circ} \mathrm{C}$ ) and circulating water at a velocity, $v$, of $0.35 \mathrm{~m} / \mathrm{s}$. As shown in Figure 1, at the pipe outlet, the thermo-hydraulic boundary condition was applied [14]. Before the application of changes in temperature, the excess pore water pressures generated during excavation were allowed to dissipate in order to isolate the thermal effects from those generated during construction and the stiffness of the soil was reset to its maximum value [13]. To guarantee numerical stability in the presence of large water flow velocities within the pipes, the PetrovGalerkin finite element method [15] was adopted. Appropriate time steps were employed to avoid the thermal and hydraulic shock problems $[16,17]$. The ground surface was maintained at a constant temperature (equal to $T_{0}=15^{\circ} \mathrm{C}$ ) throughout the analysis, while all other boundaries were considered adiabatic (apart from the exposed face, as previously described).

Table 1. Thermal material properties

\begin{tabular}{|c|c|c|}
\hline Material & $\begin{array}{c}\text { Thermal } \\
\text { conductivity } \\
\lambda(\mathrm{W} / \mathrm{mK})\end{array}$ & $\begin{array}{c}\text { Volumetric specific } \\
\text { heat capacity } \\
\rho C_{p}\left(\mathrm{~kJ} / \mathrm{m}^{3} \mathrm{~K}\right)\end{array}$ \\
\hline Concrete & 1.60 & 2615 \\
\hline London Clay & 1.79 & 1820 \\
\hline Pipe/water & 0.60 & 4180 \\
\hline
\end{tabular}

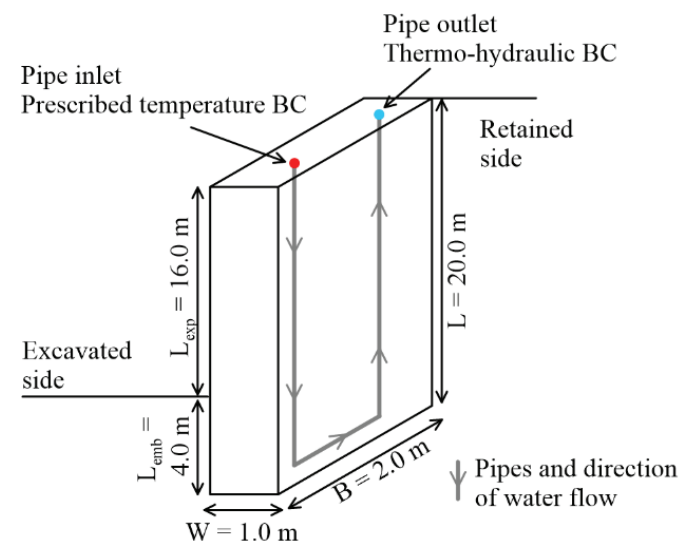

Fig. 1. Diagram of the problem and thermal boundary conditions

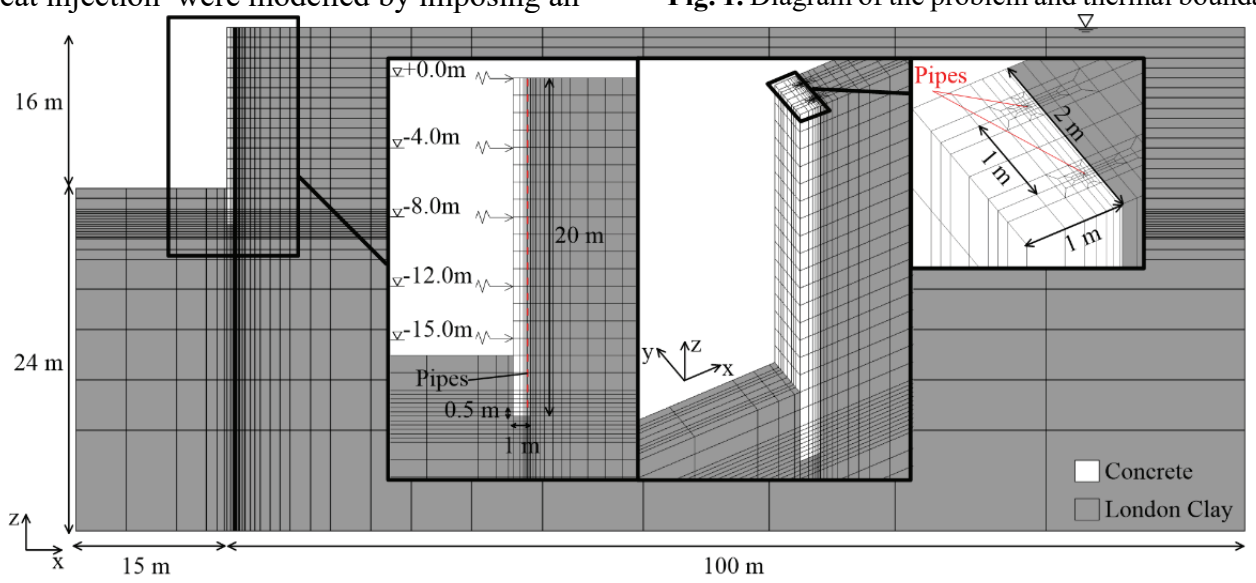

Fig. 2. Finite element mesh 


\section{Thermal design}

The proposed modelling approach for thermal design through 2D plane strain analyses consists of simulating the presence of heat exchanger pipes using onedimensional elements to replicate water flow and the advection-dominated heat transfer taking place within the pipes [18], where these correspond to a $1.0 \mathrm{~m}$-wide, zerothickness sheet. As shown in Figure 3, given the geometric simplification, in the 2D analysis the pipe's outlet is now located at the bottom of the wall $(0.5 \mathrm{~m}$ from the toe, which is consistent with the 3D model), where the water is removed from the mesh. It should be noted that the simulation of a continuous pipe element in the out-ofplane direction implies that in a 2D plane strain analysis:

(1) the heat transfer occurs at a faster rate than in a 3D analysis due to the larger contact area between the pipe and the surrounding medium;

(2) uniform temperatures in the out-of-plane direction are simulated, hence the three-dimensional temperature distribution cannot be reproduced;

(3) the simulated condition is closer to 3D problems with a large number of pipes within a wall panel.

The proposed 2D approximation ensures that the same energy is introduced in $3 \mathrm{D}$ and the equivalent $2 \mathrm{D}$ analyses by simulating the same fluid flow rate $\left(Q_{w}=v A_{p}\right)$ per unit width of wall in both models. This is achieved by adjusting the area of the pipe in $2 \mathrm{D}, A_{p}^{2 D}$, according to the following equation:

$$
A_{p}^{2 D}=\frac{A_{p}^{3 D} n_{p}}{B} \cdot 1.0 m
$$

where $A_{p}^{3 D}$ is the cross-sectional area of the pipe in 3D $\left(\mathrm{m}^{2}\right), n_{p}$ is the number of vertical pipe segments in $3 \mathrm{D}(-)$ and $B$ is the width of the wall $(\mathrm{m})$.

An additional correction is required for walls exposed to a constant temperature (CT). Under such conditions, since in 2D the pipe element is continuous in the out-ofplane direction (see Figure 3), an increased heat exchange through the wall-air interface occurs. To take this into account, a correction is proposed through which the inlet temperature in the $2 \mathrm{D}$ analysis, $T_{i n, 2 D, C T}$, is reduced with respect to the one applied in $3 \mathrm{D}\left(T_{i n, 3 D}\right)$ and calculated using the following equation:

$$
T_{i n, 2 D, C T}=T_{0}+X \cdot \Delta T_{i n, 3 D}
$$

where $X$ is a correction factor established empirically by matching the long-term heat flux per unit area, $q_{A}$, between numerous $3 \mathrm{D}$ and $2 \mathrm{D}$ analysis, calculated as:

$$
q_{A}=\frac{\left(\rho C_{p}\right)_{w} Q_{w}\left(T_{\text {in }}-T_{\text {out }}\right)}{A_{\text {wall }}}
$$

where $\left(\rho C_{p}\right)_{w}$ is the volumetric heat capacity of water $\left(\mathrm{kJ} / \mathrm{m}^{3} \mathrm{~K}\right), T_{\text {in }}$ and $T_{\text {out }}$ are, respectively, the inlet and outlet temperatures $\left({ }^{\circ} \mathrm{C}\right)$ and $A_{\text {wall }}(=L \cdot B)$ is the area of the wall panel $\left(\mathrm{m}^{2}\right)$, which differs in $3 \mathrm{D}$ and $2 \mathrm{D}$ due to the different width (see Figure 1 and 3).

It was found that $X$ depends on the proportion of wall in contact with the wall-air interface (denoted herein as $L_{\text {exp }} / L$ ) and the spacing between the pipes in the out-ofplane direction in $3 \mathrm{D}, B / n_{p}$. Indeed, these two geometric quantities characterise the increased heat transfer taking place in $2 \mathrm{D}$ when compared to the $3 \mathrm{D}$ problem. The correction factor is expressed as:

$$
X=\xi_{1}\left(\frac{B}{n_{p} \cdot 1.0 m}\right)^{\xi_{2}} \cdot\left(1+\xi_{3}\left(\frac{L_{e x p}}{L}\right)^{\xi_{4}}\right)+1.0
$$

where $\xi_{1}, \xi_{2}, \xi_{3}$ and $\xi_{4}$ are constants equal to $-0.38,0.78$, 0.83 and 2.64 , respectively, which were obtained through a regression analysis.

The previously described problem was modelled in 2D plane strain analyses employing the proposed approximations and the same mesh discretisation and lateral extents as those depicted in Figure 1 in the $\mathrm{x}-\mathrm{Z}$ plane. According to the geometrical parameters of the problem (i.e. $A_{p}^{3 D}=5.87 \times 10^{-4} \mathrm{~m}^{2}, n_{p}=2, B=2.0 \mathrm{~m}$ ), the area of the pipe in the 2D plane strain analysis calculated through Equation (1) is equal to $5.87 \times 10^{-4} \mathrm{~m}^{2}$. For the CT analysis, the inlet temperature computed according to Equations (2) and (4) is equal to $21.7^{\circ} \mathrm{C}$ (with $L_{\text {exp }} / L=$ 0.8 and $B / n_{p}=1.0, T_{0}=15^{\circ} \mathrm{C}, \Delta T_{i n, 3 D}=15^{\circ} \mathrm{C}$ ). Figure 4 compares the evolution of the heat flux with time computed in $3 \mathrm{D}$ and respective $2 \mathrm{D}$ analyses for both the $\mathrm{NF}$ and CT cases. At the beginning of the analysis, the 2D simulations overestimate the heat flux obtained in $3 \mathrm{D}$, due to the faster heat transfer simulated in the former case. In the medium to long-term, a good match in the heat flux is obtained, with differences of $1.2 \mathrm{~W} / \mathrm{m}^{2}$ and $0.7 \mathrm{~W} / \mathrm{m}^{2}$ for the NF and CT analyses, respectively. The proposed approximations were applied on a wide range of cases [19], showing a good agreement and hence demonstrating the suitability of the proposed modelling approach and 2D approximations to provide estimations of the long-term thermal performance of thermo-active walls.

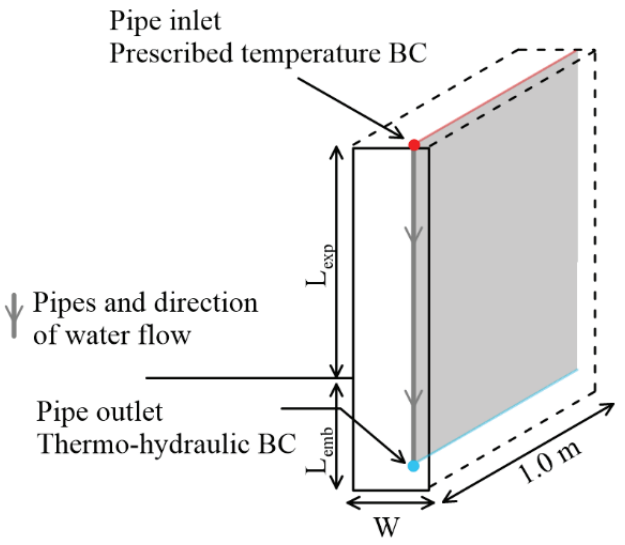

Fig. 3. Schematic of the modelling approach for thermal design in $2 \mathrm{D}$ analyses 


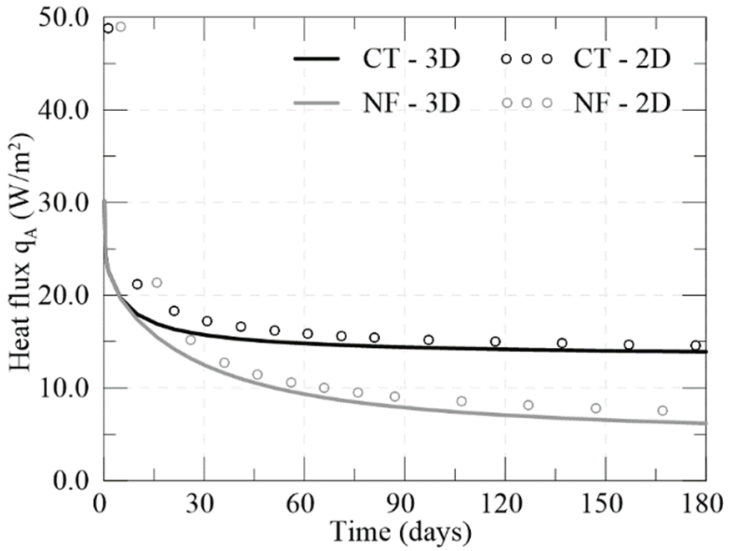

Fig. 4. Comparison of heat flux with time

\section{Thermo-mechanical design}

The method proposed for thermo-mechanical design aims at reproducing the average thermally-induced forces per metre width of wall panel to which thermo-active walls are subjected. Indeed, further studies have shown that the method described in the previous section, while yielding a good estimate of the thermal performance, does not allow an accurate reproduction of the thermo-mechanical response. To address this limitation, the new method was developed such that only simple analyses where the heat exchange is simulated through the application of thermal boundary conditions are required, thus avoiding the use of elements simulating heat exchanger pipes, which require advanced numerical methods [15].

Figure 5 presents a schematic illustration of the proposed method. First, through a thermal simulation of the wall problem in plan view (" $2 \mathrm{D}$ plan analyses" of exposed and embedded sections, see respectively Figure 5 (a) and (b)), an average temperature, $T_{i, 2 D}$, is evaluated using the following expression:

$$
T_{i, 2 D}=\frac{L_{e x p}}{L} T_{i, A v, \exp }+\frac{L_{e m b}}{L} T_{i, A v, e m b}
$$

where $L_{\text {exp }}$ and $L_{e m b}$ are the exposed and embedded lengths of the wall $(\mathrm{m})$, respectively, $L$ is the total length of the wall (m) and $T_{i, A v \text {,exp }}$ and $T_{i, A v \text {,emb }}$ are the average temperatures at time instant $t=t_{i}$ across the width of the panel $(B)$ where the pipes are located for the exposed and embedded sections of the wall, respectively (i.e. along line A-B in Figure 5 (a) and (b)). For the simulation of the presence of the heat exchanger pipes in this analysis, a constant temperature boundary condition is prescribed at their positions within the wall section. Assuming that the temperature along the pipes varies linearly, the temperature applied at these points is taken to be, approximately, $T_{i n, 3 D}-\Delta T / 2$ (see Figure 5 (a) and (b)), where $\Delta T$ is the temperature difference between the inlet and outlet of the pipes. This quantity should be characteristic of the heat extraction/injection rates reported for thermo-active walls in the literature (i.e. 10 to $30 \mathrm{~W} / \mathrm{m}^{2}$, see [3], [20] and [21]).
The computed variation with time of the average temperature, $T_{i, 2 D}$, is then applied as a boundary condition along the corresponding position of the pipes in the original geometry (i.e. along line C-D in Figure 5 (c)) in a 2D coupled THM plane strain analysis. For details on the thermo-mechanical behaviour of thermo-active walls in coupled THM analyses it is referred to [6] and [22].

For the case described in section 2, the temperature difference between the pipe inlet and outlet, $\Delta T$, was assumed to be $1.0^{\circ} \mathrm{C}$. Note that this value could have been extracted from the 3D analysis, but since the objective of the method is to avoid performing this type of analysis, an estimate is preferred here. Consequently, a constant temperature of $29.5^{\circ} \mathrm{C}$ (given that $T_{i n, 3 D}=30^{\circ} \mathrm{C}$ ) was imposed at the nodes where the pipes are located in the 3D analysis. In order to account for the different wall-air interactions, two different plan analyses of the exposed section were performed with either a NF or CT boundary condition. A period of 6 months was simulated and, for each step of the analysis, $T_{i, A v \text {,exp }}$ and $T_{i, A v, \text { emb }}$ were evaluated in order to compute $T_{i, 2 D}$. This was then applied as a time-dependent boundary condition along the position of the pipe (i.e. at $0.1 \mathrm{~m}$ from the concrete edge on the retained side) in a fully coupled plane strain THM analysis.

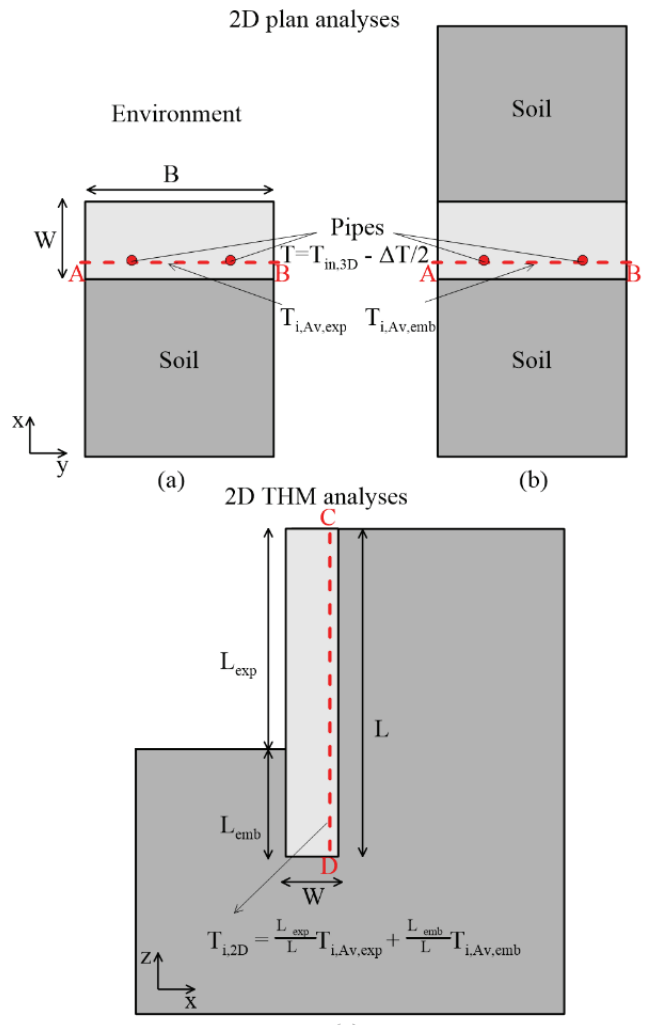

(c)

Fig. 5. Diagram of the modelling approach for thermomechanical design in 2D analyses (a) 2D plan analysis for exposed section, (b) 2D plan analysis for embedded section and (c) 2D THM analysis simulated with temperature boundary condition. 
It should be noted that, in order to guarantee the same conditions prior to the commencement of the heat exchange, the construction sequence up to this stage of the analysis was identical in the $3 \mathrm{D}$ and $2 \mathrm{D}$ models. Furthermore, the mesh discretisation and dimensions for both the 2D plan analyses and the 2D THM analyses were the same as those employed in $3 \mathrm{D}$ in the $\mathrm{x}-\mathrm{y}$ and $\mathrm{x}-\mathrm{z}$ planes, respectively.

In order to demonstrate the effectiveness of the proposed method, the axial forces, bending moments and vertical wall displacements computed in $3 \mathrm{D}$ and $2 \mathrm{D}$ for the two boundary conditions considered along the exposed face of the wall are compared. These results are presented in terms of changes from the beginning of the application of temperature changes.

The profiles of changes in average axial force and bending moment per meter width of the wall are shown in Figure 6 (a) and (b), respectively. The results are reported for two different time instants, i.e. the short-term (ST) and long-term (LT), which correspond to 3 days and 6 months from the beginning of the heat exchange, respectively. The change in axial forces computed in 2D compare very well with those obtained by the 3D model, for both time instants, with maximum differences limited to $\pm 1.5 \mathrm{kN} / \mathrm{m}$.

Similarly, the average bending moment is well reproduced by the $2 \mathrm{D}$ analysis. Indeed, in the short-term, negligible differences between the values computed in 3D are observed. In the long term, for the CT case, the maximum change in bending moment, which occurs within the exposed part of the wall, is overestimated in 2D by approximately $30 \mathrm{kNm} / \mathrm{m}(9 \%)$; for the NF case, the $2 \mathrm{D}$ analysis predicts a slightly larger negative change in bending moment at the position of the base slab (i.e. $15.0 \mathrm{~m}$ depth).

Figure 7 displays the variation of the thermallyinduced vertical displacement at the top of the wall with time for both boundary conditions. Both the magnitude and rate of change with time are well reproduced in the 2D analysis, with differences of less than $0.5 \mathrm{~mm}(9 \%)$ when compared to the values computed in the $3 \mathrm{D}$ analysis.

Similar to the previously described method for thermal design, the proposed methodology to simulate the thermomechanical behaviour has been checked against numerous 3D analysis with varying geometric and thermal parameters, with an excellent agreement being observed in all cases [22]

It should be noted that, as previously stated, nonuniform temperatures across the width of the wall panel develop in three-dimensional analyses simulated with the presence of heat exchanger pipes. As observed by [23], this temperature difference affects the distribution of axial forces along this dimension, since it induces differential thermal expansion between different portions of wall, leading to the development of internal actions and reactions. It has been observed that the additional forces are notably larger than the average axial force shown in Figure 6 and should thus be considered during design. While a 2D plane strain analysis cannot account for such a phenomenon, an analytical procedure has been developed to provide an estimate of the generated forces [22]. (a) Change in axial force $(\mathrm{kN} / \mathrm{m})$ Change in axial force $(\mathrm{kN} / \mathrm{m})$

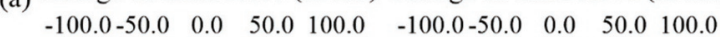

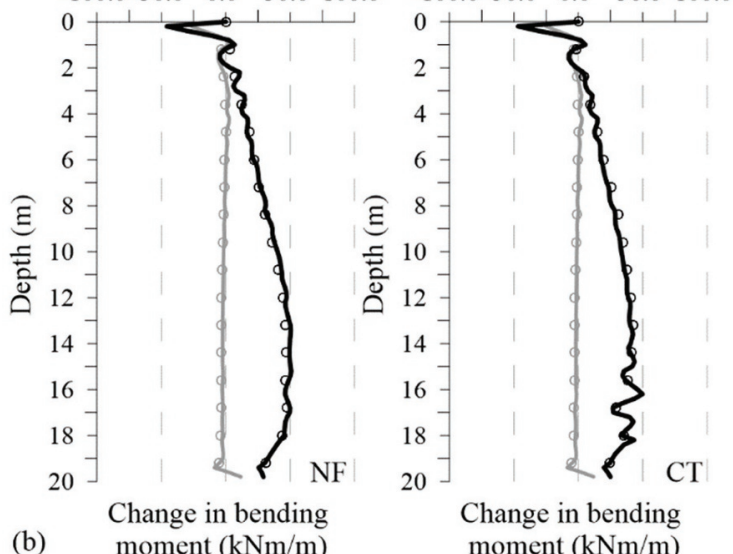

(b) moment $(\mathrm{kNm} / \mathrm{m})$

moment $(\mathrm{kNm} / \mathrm{m})$

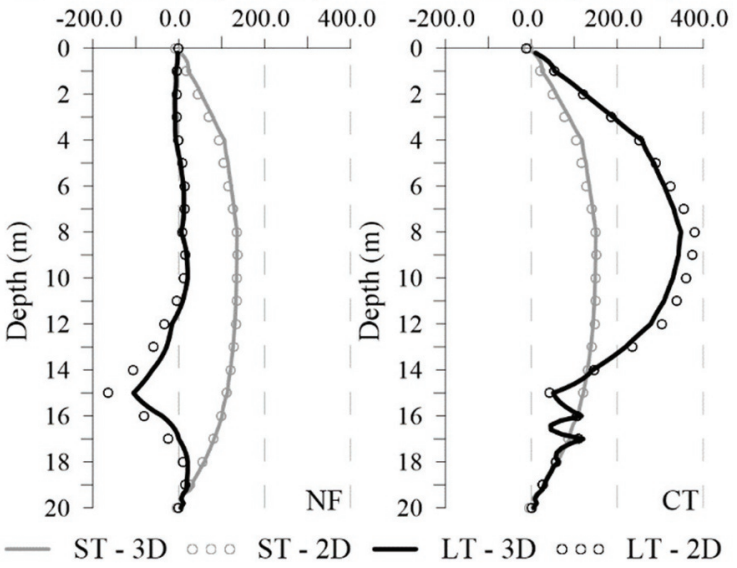

Fig. 6. Variations in depth of wall forces in terms of (a) axial force and (b) bending moment

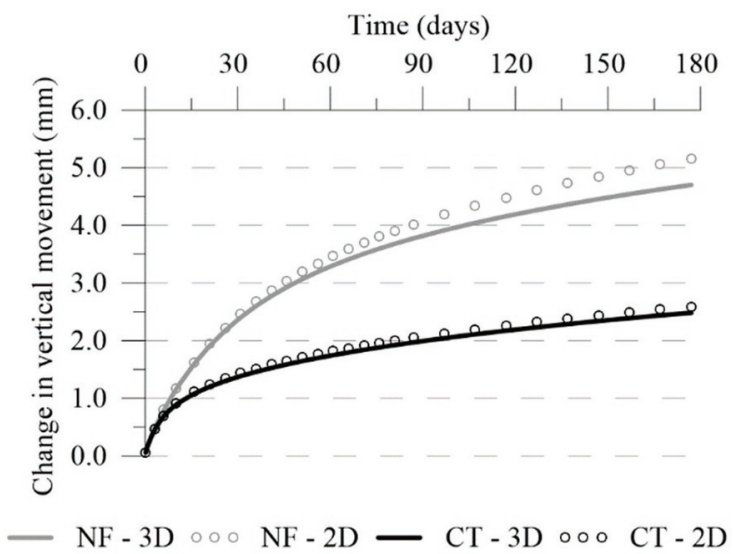

Fig. 7. Change in vertical movement of top of wall with time

\section{Conclusions}

This paper presents two new modelling approaches for the accurate simulation of thermo-active walls by means of two-dimensional (2D) plane strain analyses. Since thermo-active walls are employed to provide both energy and stability to buildings, the proposed approximations were determined to allow an estimation of their thermal performance and thermo-mechanical response. The 
objective of these methods is to approximate the behaviour obtained by three-dimensional (3D) analyses where the presence of heat exchanger pipes is simulated explicitly, thus allowing considerable savings in computational effort by reducing the size of the problem. Given the known effect of the simulated boundary condition along the exposed face of the wall on the temperature distributions and, hence, on the response of the structure, two extreme scenarios, namely an insulated wall (NF) and a wall face maintained at a constant temperature (CT) were considered in this study.

The approximations for the thermal design were established for 2D analyses which include heat exchanger pipes. To ensure an equivalent energy input in $3 \mathrm{D}$ and $2 \mathrm{D}$ analyses, the same water flow rate has to be simulated in both problems, which is achieved by adjusting the crosssectional area of the 2D element simulating the pipes in the $2 \mathrm{D}$ analysis. For walls maintained at a constant temperature, an additional correction is required to account for the increased heat transfer in 2D under such conditions. The proposed correction factor $X$ reduces the inlet temperature applied in $2 \mathrm{D}$ analyses to simulate the same heat transfer rate as in the 3D problem.

For the thermo-mechanical design of thermo-active walls, a modelling procedure which consists solely of applying prescribed temperature boundary conditions, rather than modelling explicitly the existence of heat exchanger pipes, was developed. It requires an initial analysis of the problem in plan view to obtain the variation with time of the average temperature across the width of the wall panel along the position of the pipes. To account for the wall-air interaction, both the exposed and embedded sections are simulated and the average temperature is determined as the weighted average of the results obtained by the two analyses according to the excavation depth. The obtained average temperature is then applied as a time-dependent thermal boundary condition in a 2D plane strain THM analysis of the wall in cross-section.

This paper demonstrates the applicability and accuracy of the proposed modelling procedures by simulating a hypothetical thermo-active wall problem. It is shown that, by simulating the problems using $2 \mathrm{D}$ plane strain analyses employing the proposed design methods, very good estimates of the thermal performance and structural response of the wall are obtained. Therefore, simpler and more computationally efficient analyses can be used to evaluate the complex behaviour of this type of structures, facilitating their design.

The PhD programme of the first author is sponsored by the Department of Civil and Environmental Engineering, Imperial College London, through a Skempton Scholarship.

\section{References}

1. Sterpi, D., Angelotti, A., Habibzadeh-Bigdarvish, O. \& Jalili, D. J. Assessment of thermal behaviour of thermo-active diaphragm walls based on monitoring data. Rock Mech. Geotech. Eng., 10, 1145-1153 (2018).
2. Xia, C., Sun, M., Zhang, G., Xiao, S. \& Zou, Y. Experimental study on geothermal heat exchangers buried in diaphragm walls. Energy Build., 52, 50-55 (2012).

3. Brandl, H. Energy foundations and other thermoactive ground structures. Geotechnique, 56, 81-122 (2006).

4. Di Donna, A., Cecinato, F., Loveridge, F. \& Barla, M. Energy performance of diaphragm walls used as heat exchangers. Proc. Inst. Civ. Eng. Geotech. Eng., 180, 232-245 (2017).

5. Bourne-Webb, P. J., Bodas Freitas, T. M. \& da Costa Gonçalves, R. A. Thermal and mechanical aspects of the response of embedded retaining walls used as shallow geothermal heat exchangers. Energy Build., 125, 130-141 (2016).

6. Sailer, E., Taborda, D. M. G., Zdravković, L. \& Potts, D. M. Fundamentals of the coupled thermo-hydromechanical behaviour of thermo-active retaining walls. Comp. Geotech., 109, 189-203 (2019).

7. Potts, D. M. \& Zdravković, L. Finite Element Analysis in Geotechnical Engineering: Theory. London, Thomas Telford, (1999)

8. Cui, W., Potts, D. M., Zdravković, L., Gawecka, K. A. \& Taborda, D. M. G. An alternative coupled thermo-hydro-mechanical finite element formulation for fully saturated soils. Comp. Geotech., 94, 22-30 (2018).

9. Gawecka, K. A., Taborda, D. M. G., Potts, D. M., Sailer, E., Cui, W. \& Zdravković, L. Finite element modelling of heat transfer in ground source energy systems with heat exchanger pipes. ASCE Int. J. Geomech., 20 (5), 1-14, (2019).

10. Gawecka, K. A., Potts, D. M., Cui, W., Taborda, D. M. G. \& Zdravković, L. coupled thermo-hydromechanical finite element formulation of onedimensional beam elements for three-dimensional analysis. Comp. Geotech., 104, 29-41 (2018).

11. Makasis, N., Narislio G.A., Bidarmaghz, A., Johnston, I.W., Zhong, Y. The importance of boundary conditions on the modelling of energy retaining walls. Comp. Geotech., 120, 1-13 (2020).

12. Taborda, D. M. G., Potts, D. M. \& Zdravković, L. On the assessment of energy dissipated through hysteresis in finite element analysis. Comp. Geotech., 71, 180-194 (2016).

13. Gawecka, K. A., Taborda, D. M. G., Potts, D. M., Cui, W., Zdravković, L. \& Haji Kasri, M. S. Numerical modelling of thermo-active piles in London Clay. Proc. Inst. Civ. Eng. Geotech. Eng., 170, 201-219 (2017).

14. Cui, W., Gawecka, K. A., Potts, D. M., Taborda, D. M. G. \& Zdravković, L. Numerical analysis of coupled thermo-hydraulic problems in geotechnical engineering. Geomech. Energy Environ., 6, 22-34 (2016).

15. Cui, W., Gawecka, K. A., Potts, D. M., Taborda, D. M. G. \& Zdravković, L. A Petrov-Galerkin finite element method for 2D transient and steady state highly advective flows in porous media. Comp. Geotech., 100, 158-173 (2018). 
16. Cui, W., Gawecka, K. A., Taborda, D. M. G., Potts, D. M. \& Zdravković, L. Time-step constraints for finite element analysis of two-dimensional transient heat diffusion. Comp. Geotech., 108, 1-6 (2019).

17. Cui, W., Gawecka, K. A., Taborda, D. M. G., Potts, D. M. \& Zdravković, L. Time-step constraints in transient coupled finite element analysis. Int. J. Numer. Meth. Eng., 106, 953-971 (2016).

18. Cui, W., Potts, D. M., Zdravković, L., Gawecka, K. A., Taborda, D. M. G. \& Tsiampousi, A. A coupled thermo-hydro-mechanical finite element formulation for curved beams in two-dimensions. Comp. Geotech., 103, 103-114 (2018).

19. Sailer, E. Numerical modelling of thermo-active retaining walls. $\mathrm{PhD}$ thesis. Imperial College London (2020).

20. Angelotti, A. \& Sterpi, D. On the performance of energy walls by monitoring assessment and numerical modelling: a case in Italy Environ.Geotech., 1-8 (2018).

21. Sterpi, D., Tomaselli, G. \& Angelotti, A. Energy performance of ground heat exchangers embedded in diaphragm walls: Field observations and optimization by numerical modelling. Renewable Energy, (2018).

22. Sailer, E., Taborda, D. M. G., Zdravkovic, L. \& Potts, D. M. Proc. Inst. Civ. Eng. Geotech. Eng, (ahead of print), (2020).

23. Sterpi, D., Coletto, A. \& Mauri, L. Investigation on the behaviour of a thermo-active diaphragm wall by thermo-mechanical analyses Geomech. Energy Environ., 9, 1-20 (2017). 